AJHSE Vol: 2 (2): 72-81, 2021

DOI: $10.52417 /$ ajhse.v2i2.142

Accepted Date: August 20, 2021

(C) 2021. CC License 4.0

www.ajhse.org

\title{
EMBRYO-LARVAL TOXICITY OF ANTI-FUNGUS CHEMICALS USED AS PROPHYLACTIC AGENTS ON CLARIAS GARIEPINUS (BURCHELL, 1822)
}

\author{
${ }^{* 1}$ Opute, P. A. \& ${ }^{2}$ Aisirhiowen, C.A.
}

${ }^{*} 1 \& 2$ Department of Animal and Environmental Biology, Faculty of Life Sciences, University of Benin, Benin City, Nigeria

*Corresponding Author's E-mail: ashibudike.opute@uniben.edu

\begin{abstract}
$\mathrm{E}$ mbryo-larval toxicity test of selected anti-fungus chemicals used as prophylactic agents on the African catfish (Clarias gariepinus) was conducted to assess the comparative efficacy as well as the toxicity of the different chemicals. Measured endpoints included hatching, embryo and larval survival, and larval growth. Iodine $\left(100 \mathrm{mg} \mathrm{L}^{-1}\right)$, hydrogen peroxide $\left(250 \mathrm{mg} \mathrm{L}^{-1}\right)$, malachite green $\left(5 \mathrm{mg} \mathrm{L}^{-1}\right)$ and formalin $\left(250 \mathrm{mg} \mathrm{L}^{-1}\right)$ were used as prophylactic agents. The eggs were spread on an incubating raft and continuously dipped in the treatment chemical for 15 minutes. After 48 hours, the mean hatch rate was highest in formalin-treated embryos (70\%). Iodine treatment resulted in a hatch rate of $36.7 \%$, which was slightly less than half that of the formalin treatment. Both hydrogen peroxide and malachite green resulted in $60.0 \%$ hatch rates. The results indicate that formalin-treated embryos performed significantly better than all the other chemicals. The highest percentage survival rate of $63.3 \%$ was observed in formalin at $72 \mathrm{hph}$ and $56.7 \%$ after $168 \mathrm{hph}$. The lowest survival rate (10\%) was observed in the iodine treatment group and closely followed by the group treated with malachite green (16.7\%). Except for malachite green, which inhibited growth, the prophylactic treatments did not affect the growth performance of fry. This study presents evidence that can be used to support the use of formalin and hydrogen peroxide as prophylactic treatments in the early stages of $C$. gariepinus, although caution should be exercised due to the possibility of toxicity at higher concentrations and for longer periods of exposure.
\end{abstract}

Keywords: Clarias gariepinus, prophylactic agents, embryo toxicity, hatch success, survival, growth

COPYRIGHT: The Author(s) completely retain the copyright of this published article.

OPEN ACCESS: The Author(s) approves that this article remains permanently online in the open access (OA) model

QA: This Article is published in line with "COPE (Committee on Publication Ethics) and PIE (Publication Integrity \& Ethics)". 


\section{INTRODUCTION}

The African catfish (Clarias gariepinus) is a common food fish that is farmed both within and outside of its natural range of tropical and subtropical environments. Its ecosystems include seasonal flooding areas as well as stable lakes, ponds, and swamps. This fish species has evolved to survive in adverse environmental conditions throughout its evolutionary journey (Chwastowska-Siwiecka et al., 2019). The suitability of $C$. gariepinus for aquaculture across its distributional range was first recognized in the middle of the 1980s. This species is now cultured for commercial or subsistence purposes in almost every country in Sub-Saharan Africa, as well as North Africa and many other countries around the world, over the last 30 years (Abdel-Hay et al., 2019). The ability to withstand adverse environmental conditions, use atmospheric oxygen, and efficiently convert various feedstuffs to the flesh is an advantage of the African catfish as an aquaculture candidate cultured in many parts of the world (Okomoda, 2019). Until the growthout stage, Clarias gariepinus is primarily cultured on an intensive scale at the hatchery. It is commercially important due to its disease tolerance, high fecundity, and ease of larval development in captivity.

However, there are still significant challenges in larval production, primarily due to infection outbreaks, especially at the early stages of development. As a result, diseases are a major stumbling block to the global expansion of aquaculture. These outbreaks, therefore, must be prevented and/or managed to preserve healthy fry stocks. Fish are immediately exposed to bacteria in water from their eggs and early stages. Many farmers try to prevent disease outbreaks by using antibiotics and other chemicals as a preventative measure. Several problems, such as high mortality during the incubation of eggs in hatcheries, are a result of fungal and bacterial diseases, as well as parasitic infections. Aquatic fungi (Saprolegniales) cause the most common fungal infection in fish, and infected eggs/larvae are covered in a cotton-like growth. They are abundant in natural water sources used by fish hatcheries, and they often cause serious disease problems. Also, C. gariepinus is frequently infected with motile aeromonad septicemia, which is caused by the Gram-negative bacteria Aeromonas hydrophila (Alimuddin et al. 2018).

Furthermore, commonly found ectoparasites associated with the culture of C. gariepinus are Dactylogyrus, Trichodinia, Costia, Chilodonella and Gyrodactylus. Iodine, hydrogen peroxide, malachite green, formalin, copper sulfate, potassium permanganate, and sodium chloride are some of the chemotherapeutics widely used for the treatment and prevention of fungal and bacterial infections as well as external parasites. However, just a few studies have been conducted on the comparative effectiveness of these chemicals as effective prophylactic agents, as well as testing their ability to elicit short-term toxicity in the early stages of $C$. gariepinus. Therefore, this study was carried out to determine the comparative efficacy of these chemicals as an effective prophylactic treatment for the eggs of Clarias gariepinus and to assess the possible implications of the short-term toxicity of these prophylactic chemicals to their early stages of development.

\section{MATERIALS AND METHODS EXPERIMENTAL DESIGN}

One male and female broodstock of Clarias gariepinus with an average weight of $1.8 \mathrm{~kg}$ were purchased from the aquaculture unit of the Department of Fisheries and Aquaculture, Faculty of Agriculture, University of Benin, and maintained in the animal house at the Department of Animal and Environmental Biology. The female broodstock was 
artificially spawned at a rate of $0.5 \mathrm{ml} / \mathrm{kg}$ of body weight by intramuscular injection of Ovaprim manufactured by Syndel Canada. For ease of injection and stripping of eggs, the broodstock was anaesthetized with five drops of quinaldine (added into 3 litres of water in plastic bowls). A single dose of ovaprim was injected intramuscularly (2-3 $\mathrm{cm}$ ) in the direction of the tail at an angle of $30-45^{\circ}$ of the dorsal fin. The injected fish was kept in a separate tank and allowed a latency time of 11 hours. After 11 hours (latency period) the injected female broodstock was removed from its tank, weighed and then stripped by gently pressing the abdomen from the pectoral fin to the genital papilla into well labelled dry bowls with the thumb. After dissecting it, male broodstock milt was extracted, and the sperm collected by testis laceration with a clean razor blade into $25 \mathrm{ml}$ of normal saline $(0.9 \% \mathrm{NaCl}$ in water $)$ in a tub.

The male's sperm was mixed with the female's eggs and spread over a plastic netting substrate mounted in a $50 \mathrm{~L}$ bowl that held about $20 \mathrm{~L}$ of water. The water temperature used was $27^{\circ} \mathrm{C}$, and the $\mathrm{pH}$ was 6.6 (controlled using soda ash and measured using a portable $\mathrm{pH}$ meter). Thirty (30) eggs were counted and removed from the original mixture and spread in smaller bowls containing $2 \mathrm{~L}$ of water to be used for embryo toxicity on a netting substrate. The small bowls were all correctly labelled with the codes $T_{1}, T_{2}, T_{3}, T_{4}$ and $T_{5}$ representing the different prophylactic treatments with formalin $\left(250 \mathrm{mg} \mathrm{L}^{-1}\right)$, iodine $\left(100 \mathrm{mg} \mathrm{L}^{-1}\right)$, hydrogen peroxide $\left(250 \mathrm{mg} \mathrm{L}^{-1}\right)$, malachite green $(5 \mathrm{mg}$ $\mathrm{L}^{-1}$ ) and control, respectively. The embryo-toxicity test was conducted by the exposure to the treatment chemicals of freshly fertilized eggs (before the beginning of cleavage i.e 40minutes post-fertilization.

The eggs were spread on an incubating raft and continuously dipped in the appropriate solution containing the treatment chemical for 15 minutes and observed until hatching. There were three replications in the study. Egg fertilization was calculated using the most widely used method for estimating fertilization rate in previous studies, as described by Ella (1987). This entails keeping an eye on a small portion of the unfertilized egg from the time it is stripped until the eggs become completely opaque (dead). The hatching rate was calculated using a simple proportion and assuming that the fries were evenly distributed in the water. The percentage of survival was calculated by counting the number of live fry at the first feeding and expressing it as a percentage of the initially hatched fry.

\section{PHYSICOCHEMICAL ANALYSIS OF TREATMENT WATER}

The physicochemical parameters of the various treatment water samples, including $\mathrm{pH}$, Temperature, Conductivity, Total Dissolved Solids (TDS), and Dissolved Oxygen (DO), were measured throughout the study using standard methods (APHA 2005).

\section{DATA ANALYSIS}

The statistical package for social sciences (SPSS version 21) was used to analyze all the data. The treatment means \pm standard error of the mean (SEM) was used to present the data. The data were analyzed using one-way ANOVA to test the effects of the different prophylactic treatments on the embryo, with significance set at $\mathrm{P}<0.05$. To compare the means of all treatments, Tukey's posthoc test was used. 


\section{RESULTS AND DISCUSSION WATER QUALITY}

For all experiments, the mean ( \pm SEM) water quality parameters recorded for the spawning bowls were as follows: $\mathrm{pH}$ values ranged from $7.16 \pm 0.05$ to $7.65 \pm 0.06$; electric conductivity ranged from $64.43 \pm 0.57$ in water to $740 \pm$ 10.65 in Hydrogen peroxide; dissolved oxygen was $0.95 \pm 0.29$ in Hydrogen peroxide and recorded highest values in water $(4.52 \pm 0.19)$; the temperature was generally uniform, ranging from $26.60 \pm 0.17$ to $26.80 \pm 0.14$; and total dissolved solid was significantly lower in water $(34.13 \pm 1.88)$. Table 1 shows the water quality parameters for all hatching bowls in each experiment.

Table 1: Concentrations of the physico-chemical parameters of the test media

\begin{tabular}{|c|c|c|c|c|c|}
\hline PARAMETERS & Water & Formalin & Iodin & Malachite Green & Hydrogen Peroxide \\
\hline pH & $7.65 \pm 0.06$ & $7.39 \pm 0.04$ & $7.55 \pm 0.06$ & $7.16 \pm 0.06$ & $7.37 \pm 0.06$ \\
\hline Electric conductivity (EC) $\mu \mathrm{Scm}-1$ & $64.4 \pm 3.57^{\mathrm{a}}$ & $138.13 \pm 3.95^{\mathrm{b}}$ & $239.83 \pm 7.36^{\mathrm{c}}$ & $326.0 \pm 6.16^{\mathrm{d}}$ & $740 \pm 10.65$ \\
\hline Dissolved Oxygen (DO) mg/L & $4.52 \pm 0.19^{\mathrm{a}}$ & $4.16 \pm 0.02^{\mathrm{ab}}$ & $3.97 \pm 0.11^{\mathrm{b}}$ & $3.22 \pm 0.14^{\mathbf{b}}$ & $0.95 \pm 0.29^{c}$ \\
\hline Temperature ${ }^{0} \mathrm{C}$ & $26.73 \pm 0.13$ & $26.75 \pm 0.14$ & $26.7 \pm 0.15$ & $26.6 \pm 0.17$ & $26.8 \pm 0.14$ \\
\hline Total dissolved solid (TDS) & $34.13 \pm 1.88^{\mathrm{a}}$ & $73.2 \pm 5.55^{\mathrm{b}}$ & $134.695 \pm 3.90^{c}$ & $172.78 \pm 3.27^{\mathrm{d}}$ & $392.2 \pm 5.64^{\mathrm{e}}$ \\
\hline
\end{tabular}

Data are presented as mean \pm SEM. Different letters indicate significant differences between treatments.

The health and performance of fish reared in static systems are influenced by water quality. Water quality is not just a cosmetic consideration in fish culture; it is a critical component in fishery management (Opute and Odion, 2021). Among the parameters investigated in this study, electrical conductivity and total dissolved solids differed significantly across treatment groups. Similarly, the oxygen level in the iodine, malachite green, and, most notably, the hydrogen peroxide tanks was reduced. Rowland et al. (2006) found that using formalin as a prophylactic drug resulted in a significant deterioration of water quality at temperatures above $24{ }^{\circ} \mathrm{C}$, with DO dropping from 8.5-10.7 $\mathrm{mg} \mathrm{L}^{-1}$ to stressful levels of $1.2-1.7 \mathrm{mg}^{\mathrm{L}-1}$ within 36 hours of treatment. They concluded that formaldehyde is a strong reducing agent, combining with oxygen to produce formic acid, which then combines with oxygen to produce carbon dioxide and water; the process may be mediated by bacterial metabolism. Although, the temperature of the various treatment tanks in this study remained relatively constant at $26^{\circ} \mathrm{C}$, the presence of the prophylactic agents resulted in a deterioration of water quality, but with no observable trend. Water quality parameters may also have an impact on the prophylactic efficacy or toxicity in the aquatic environment. Iodine is more toxic to embryos below $\mathrm{pH} 6$ and less effective as a disinfectant in environments with a pH of 8 or higher (Sipos et al. 2020).

\section{HATCHING AND SURVIVAL RATE}

The embryo prophylactic treatments had a significant effect on the hatching rate $(\mathrm{P}>0.05)$. After 48 hours, the mean hatch rate was highest in formalin-treated embryos (70 \%) and control (water) embryos (69.9\%), which were statistically comparable. Iodine treatment resulted in a hatch rate of $36.7 \%$, which was slightly less than half that of the control and formalin treatments. Hydrogen peroxide treatment of embryos resulted in a $60.0 \%$ hatch rate, whereas 
malachite green treatment resulted in a $60 \%$ hatch rate (Figure 1). The results indicate that both formalin and hydrogen peroxide-treated embryos hatched at a rate comparable to the control treatment, although formalin performed significantly better than hydrogen peroxide.

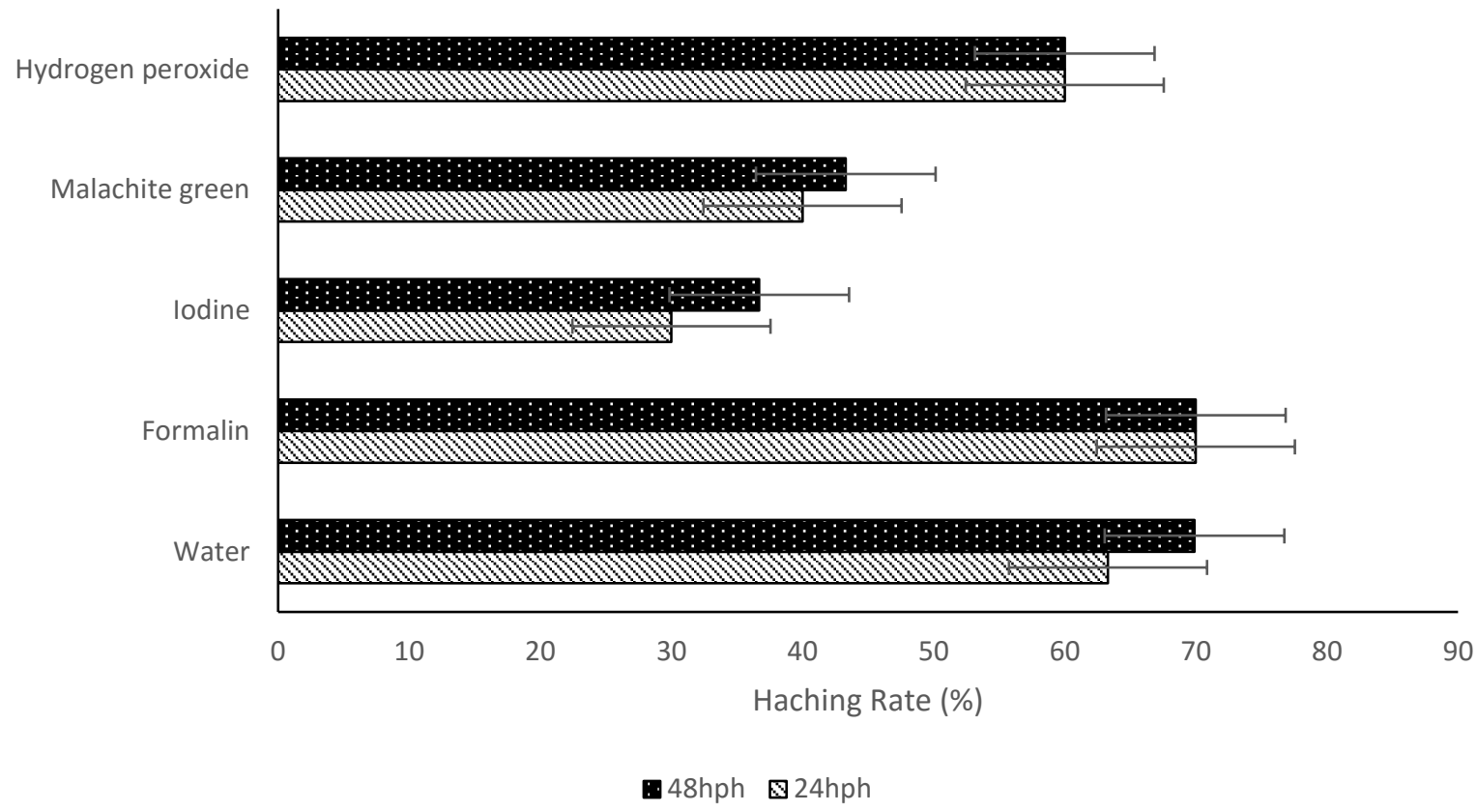

Figure 1: Hatching rates of catfish eggs treated with prophylactic chemicals: formalin, hydrogen peroxide, iodine, malachite green and water after 24hours (24hph) and 48 hours (48hph)

The survival rate of $C$. gariepinus fry exposed to the different prophylactic agents was monitored from $72 \mathrm{hph}$ to 168hph (Figure 2). The highest percentage survival rate of $63.3 \%$ was observed in formalin at $72 \mathrm{hph}$ and $56.7 \%$ after $168 \mathrm{hph}$. The lowest survival rate $(10 \%)$ was observed in the iodine treatment group and closely followed by the group treated with malachite green $(16.7 \%)$. Percent survival decreased almost approximately at the same rate from $72 \mathrm{hph}$ to $168 \mathrm{hph}$. The control group (water) recorded a lower survival rate compared to formalin and hydrogen peroxide. The survival rate among those that hatched in water was $56.7 \%$ at $72 \mathrm{hph}$ and $40 \%$ at $168 \mathrm{hph}$. 


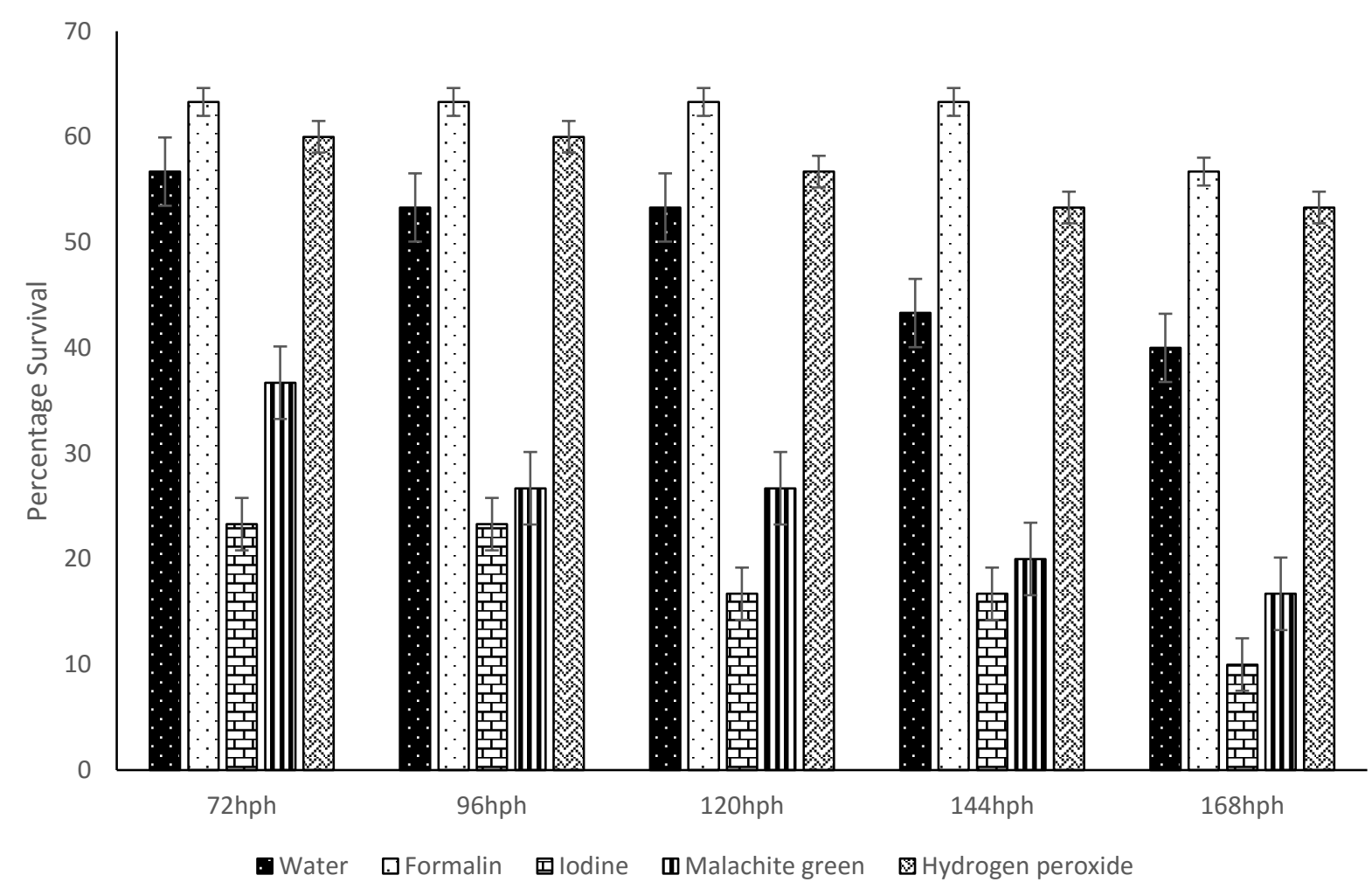

Figure 2: Survival rates of catfish fries pre-treated with prophylactic chemicals: formalin, hydrogen peroxide, iodine, malachite green and water between 72hours (72hph), 96hours (96hph), 120hours (120hph), 144hours (144hph) and 168 hours (168hph)

Despite the high fecundity of $C$. gariepinus, egg hatching rates in many African hatcheries are irregular, ranging from 8-70\% depending on the level of managerial expertise in the hatchery (Rasowo et al. 2007). The parasitization of catfish eggs by aquatic fungus and bacteria is one possible reason for the irregular hatching. A portion of the eggs fertilized via artificial fertilization are frequently not fertilized. Unfertilized fish eggs, especially those from the Saprolegniaceae family, are prone to fungal infection (Straus et. al. 2009a). This fungus creates mycelia during egg incubation, which grows and spreads from nonviable to viable eggs, suffocating them and causing death. Similarly, the average egg survival in the US catfish industry has been estimated to be around $60 \%$ (Wolters, 2001) when formalin and iodine are employed as needed to treat fungal infections in addition to other best management practices (Ataguba et al. 2013).

The efficacy of the prophylactic applications must have resulted in similar statistically significant hatching rates and survival in embryos treated with formalin and hydrogen peroxide in the current study when compared to others. Saprolegnia spp. are found in most water sources, according to Straus et al. (2009a). The standard egg/fry management techniques of renewing the water quality during incubation and rearing to first feeding under the static technique of fish breeding would have resulted in the experimental groups being reinoculated with new fungus spores from freshwater (Ataguba et al. 2013). According to Akpoilih and Adebayo (2010), the use of formalin in low doses 
significantly decreased fungal infection in Clarias gariepinus eggs and fry but had a negative impact on egg hatchability. Formalin is the primary fungicide approved for use in aquaculture in the United States, and it is effective in treating saprolegnia (Mitchell and Collins, 1997). Bailey (1984) and Bailley and Jeffry (1989) published the findings of studies involving over 200 chemicals chosen for their fungicidal activity, with formalin demonstrating the potential for fungus control on fish eggs. Although the effective concentration that can be employed depends on the time of administration, type of fish, and parasite targeted, high dosing of formalin has been shown to provide a greater hatch rate than any of the other possible antifungal agents (Akpoilih and Adebayo, 2010). All these variables could have influenced the efficacy of formalin in this present study.

Given the wide variety of aquaculture fish, it is realistic to expect the prophylactic effects of chemicals on developing embryos to be species-specific (Sipos et al. 2020). Although iodine had a low hatch success and survival rate in the present study, earlier research had found that larger doses and/or longer treatment times boosted hatching success (Chambel et al. 2014). In contrast, untreated Black Sea Turbot, Scophthalmus maximus embryos showed reduced hatching success and greater rates of malformation than untreated embryos. Although malachite green has been usually used as the best chemical substance to preserve the rainbow trout eggs against mould infections (Amani et al. 2019) and it is still being used among local hatcheries in Africa, the result from the present study indicates that it inhibited hatching and resulted in decreased survival of the fry. Meinertz et al. (1995) found detectable residues of malachite green remained in edible tissues of fish exposed to the chemical substances before hatching. The toxicity of malachite green on the embryo is responsible for the detrimental outcomes identified in this study. The use of malachite green has been prohibited by the FDA since 1991 due to health concerns among fish consumers and agricultural workers. As a result, much research has been conducted to find other alternative preventive agents for the treatment of fungal infections in farmed fish species such as $C$. gariepinus.

\section{GROWTH RATE}

The growth of Clarias gariepinus fry raised for 168 hours after exposure to the prophylactic treatments are presented in Table 2 and reveals no significant difference in the mean final weight gain (MFW) and mean weight gain (MWG) across the treatments $(P>0.05)$. The general trend in MWG reveals that fry raised in formalin (17.3 mg), water (16.7 $\mathrm{mg}$ ), iodine $(16.5 \mathrm{mg})$ and hydrogen peroxide $(14.33 \mathrm{mg}$ ) were larger than those exposed to malachite green $(10.1 \mathrm{mg})$. malachite green recorded the lowest weight gain as well as the least increase in length. 
Table 2: Growth performance of fries pre-treated with prophylactic chemicals after 168hours

\begin{tabular}{|c|c|c|c|c|c|c|}
\hline PARAMETERS & Water & Formalin & Iodin & $\begin{array}{l}\text { Malachite } \\
\text { Green }\end{array}$ & $\begin{array}{l}\text { Hydrogen } \\
\text { Peroxide }\end{array}$ & Significance \\
\hline MIW (mg) & $16.2 \pm 0.02$ & $17.1 \pm 0.05$ & $16.2 \pm 0.02$ & $14.0 \pm 0.02$ & $18.1 \pm 0.02$ & $P>0.05$ \\
\hline MFW (g) & $32.2 \pm 0.14$ & $34.1 \pm 0.03$ & $31.9 \pm 0.06$ & $24.1 \pm 0.03$ & $32.2 \pm 0.02$ & $P>0.05$ \\
\hline MIL (cm) & $2.67 \pm 0.05$ & $2.69 \pm 0.15$ & $2.66 \pm 0.06$ & $2.00 \pm 0.05$ & $2.67 \pm 0.05$ & $P>0.05$ \\
\hline MFL (cm) & $5.33 \pm 0.04$ & $5.42 \pm 0.05$ & $5.32 \pm 0.05$ & $4.10 \pm 0.05$ & $5.33 \pm 0.03$ & $P>0.05$ \\
\hline MWG (mg) & $16.7 \pm 0.02$ & $17.3 \pm 0.02$ & $16.5 \pm 0.01$ & $10.1 \pm 0.01$ & $14.3 \pm 0.02$ & $P>0.05$ \\
\hline
\end{tabular}

Data are presented as mean \pm SEM.

Except for malachite green, which inhibited growth, the prophylactic treatments had no effect on the growth performance of fry from exposed embryos in this study. The water quality parameters obtained in the present study revealed fouling and decreased dissolved oxygen. Akpoilih and Adebayo (2010) reported a similar decrease in DO in fish embryo treatment tanks after exposure to copper sulphate (CuSO4). This decrease could be attributed to the complete eradication of photosynthetic activity because of the effect of copper sulphate on non-target microscopic flora in water. Malachite green, a triphenylmethane dye has been reported to affect the girth of fish (Jang et al. 2009). The bud stage zebrafish embryos were exposed to malachite green at 125, 150, and $175 \mathrm{ppb}$ for 14 hours. Malachite green inhibited trunk development, including intersomitic vessels, in flk-1-GFP transgenic embryos. Malachite green inhibited overall growth. Similarly, when exposed to hypoxia in a laboratory and field study, a reduced growth rate was observed in different species of fish, such as the demersal fish (cod) (Chabot, 2003). As a result, both toxicity and low oxygen levels in the malachite green test groups could have contributed to the poor growth performance observed in the present study.

\section{CONCLUSION}

To treat the embryo of C. gariepinus prophylactically, we recommend a formalin dose of $250 \mathrm{mg} / \mathrm{L}$ or hydrogen peroxide at $250 \mathrm{mg} / \mathrm{L}$. This study presents evidence that can be used to support the use of formalin and hydrogen peroxide as prophylactic treatments in the early stages of $\mathrm{C}$. gariepinus, although caution should be exercised due to the possibility of toxicity at higher concentrations and for longer periods of exposure.

\section{ACKNOWLEDGMENTS}

The authors acknowledge the faculty of agriculture, University of Benin, Nigeria for supplying the fish fingerlings used in this study. We are grateful to Mr Kingsley Egun for his contributions. We are also thankful to Benin-Owena laboratory for their invaluable role in the analysis of water quality parameters.

\section{DECLARATION OF INTEREST STATEMENT}

The authors declare that they have no affiliations with or participation in any association or agency with any financial interest (educational grants; membership, jobs, consulting, expert testimony or patent-licensing arrangements), or non- 
financial interest (such as personal or professional relationships, affiliations, expertise or beliefs) in the subject matter or materials discussed in this manuscript.

\section{REFERENCES}

Abdel-Hay, M., Emam, W., Amira A. Omar, A.A., Wael F. Eltras, W.F. and Mohamed, R.A. (2019). The effects of rearing water depths and feed types on the growth performance of African catfish (Clarias gariepinus). Aquaculture Research, 51:616-622. https ://doi.org/10.1111/are.14409

Akpoilih, B.U. and Adebayo, O.T. (2010). Effect of Formalin on the Hatching Rate of eggs and Survival of larvae of the African Catish (Clarias gariepinus). J. Appl. Sci. Environ. Manage. 14 (4):31 - 34

Alimuddin, A., Putri, F.M., Wahjuningrum, D. et al (2018). Resistance against Aeromonas hydrophila infection and growth of second generation (F2) African catfish (Clarias gariepinus) using selected molecular markers. Biotropia (Bogor) 2:95-102. https://doi.org/10.11598/btb.2018.25.2.742

Amani, D.K., Soltani, M., Rajabi, I.H. and Kamali, A. (2019). The antifungal effects of Allium sativum and Artemisia sieberi extracts on hatching rate and survival of rainbow trout Oncorhynchus mykiss (Walbaum, 1792) larvae. Iranian Journal of Fisheries Sciences, 19(2):669-680

APHA (2005) Standard methods for the examination of water and wastewater, 21st edition. American Public Health Association, Washington, DC

Ataguba G.A., Okomoda, V.T. and Unde, E.S. (2013). Efficacy of Copper Sulphate as a Prophylactic Agent for Fungal Infection on Egg, and its Effect on Hatching and Early Growth of Clarias gariepinus (Burchell 1822). Asian Fisheries Science, 26: 156-166

Bailey, T.A (1984). Aspect of the biology of catfish. Clarias lazera (C and V) related to its economic cultivation. Hydrobiologia. 110:296-303.

Bialey, T.A. and Jeffry, S.M. (1989). Evaluation of 200 candidate fungicides for use in fish culture.US Fish and Wildlife Service investigation in fish control. 99Pp.

Chabot, D. (2003) Chronic non-lethal levels of hypoxia limit distribution and growth of Atlantic cod (gadus morhua) in the northern gulf of St. Lawrence, Canada. Proceedings of the Seventh International Symposium, Tallinn, Estonia, May 12-15, 2003. E.P.A., Environmental Research Laboratory, Athens, Georgia, USA. (ed) R. Gretchen and D.W. Michelle, EPA/600/R-04/049. pp. 183-206.

Chambel, J., Costa, R., Gomes, M., Mendes, S., Baptista, T. and Pedrosa. R. (2014). Hydrogen peroxide, iodine solution and methylene solution highly enhance the hatching rate of freshwater ornamental fish species. Aquaculture International, 22:1743-1751

Chwastowska-Siwiecka, I., Baryczka, M.J., Kondratowicz, J. and Winarski, R. (2019). Comparison of chemical composition and physicochemical properties of meat of males and females of African catfish (Clarias gariepinus Burchell, 1822). Bulgarian Journal of Agricultural Science, 25 (5): 1044-1051

Ella M.O. (1987). Simple calculations in fish farming. Wusen Press Ltd. Calabar, Nigeria. 64 pp. 
Jang, G.H., Park, I., Lee, S.H., Huh, T. and Lee, Y.M. (2009). Malachite green induces cardiovascular defects in developing zebrafish (Danio rerio) embryos by blocking VEGFR-2 signaling. Biochemical and Biophysical Research Communications, 382 (3):486-491

Meinertz, J.R., Stehly, G.R., Gingerich, W.H. and Allen, J.L. (1995). Residues of malachite green in eggs and fry of rainbow trout, Oncorhynchus mykiss (Walbaum), after treatment of eggs. Journal of Fish Diseases, 18:239-247.

Mitchell, A.J. and Collins, C.B. (1997). Review of the therapeutic uses of hydrogen peroxide in fish production. Aquacul. Mag. 23(3):74-79.

Okomoda, V.T., Aminem, W., Hassan, A. and Martins, C.O. (2019). Effects of feeding frequency on fry and fingerlings of African catfish Clarias gariepinus. Aquaculture, 511: 734232

Opute, P.A. and Odion, G.F. (2021). Water Renewal in Static Systems: Impacts on Productivity and Survival in Clarias gariepinus (Burchell, 1822). Tropical Freshwater Biology, 29 (2): 59-67 59.https://dx.doi.org/10.4314/tfb.v29i2.5

Rasowo, J., Okoth, E.O., Ngugi, C.C. (2007). Effects of formaldehyde, sodium chloride, potassium permanganate and hydrogen peroxide on hatch rate of African catfish Clarias gariepinus eggs. Aquaculture, 269:271-277.

Rowland, S.J., Nixon, M., Landos, M, Mifsud, C., Read, P. and Boyd, P. (2006). Effects of formalin on water quality and parasitic monogeneans on silver perch (Bidyanus bidyanus Mitchell) in earthen ponds. Aquaculture Research, 37:869-876. doi:10.1111/j.1365-2109.2006. 01505.x

Sipos, M.J., Lipscomb, T.N., Wood, A.L., Ramee, S.W. and DiMaggio, M.A. (2020). Evaluation of Three Embryo Disinfectants on Hatching Success in Four Freshwater Ornamental Fish Species. North American Journal of Aquaculture, 82:63-70. 10.1002/naaq.10118

Straus, D.L., Mitchell, A.J. Carter R.R. and Steeby, J.A. (2009a). Optimizing copper sulfate treatments for fungus control on channel catfish eggs. Journal of Aquatic Animal Health, 21:91-97

Wolters, W. R. (2001). Improving catfish spawning success. National Warmwater Aquaculture Centre News $4(1): 2$ 